\title{
GENERAL RESPONSE OBSERVED IN CYCLICALLY LOADED COHESIVE SOILS
}

\section{COMPORTAMIENTO DE SUELOS COHESIVOS BAJO CARGAS CÍCLICAS}

\author{
Andrés Nieto Leal', Victor N. Kaliakin²
}

Fecha de recepción: 20 de octubre de 2015

Fecha de aprobación: 4 de febrero de 2016

Referencia: A. N. Leal, V. N. Kaliakin (2016). General response observed in cyclically loaded cohesive soils. Ciencia e Ingeniería Neogranadina, 26 (1), pp. 21-39, DOI: http://dx.doi.org/10.18359/rcin.1673

\section{RESUMEN}

El comportamiento de suelos cohesivos sometidos a cargas cíclicas es afectado por diferentes factores; entre los más importantes se encuentran las características del suelo, estado actual e historia de esfuerzos, y condiciones específicas del ensayo. Desde inicios de 1960 varias investigaciones se han realizado con el objetivo de entender el comportamiento de estos suelos; éstas se han efectuado en una gran variedad de suelos cohesivos con diferentes índices de plasticidad, relación de sobreconsolidación, y diferentes condiciones de ensayo (cargas cíclicas). El objetivo de este trabajo es recopilar los resultados de las investigaciones más relevantes y presentar, en términos generales, el comportamiento de suelos cohesivos sujetos a cargas cíclicas. Además, se han identificado las principales características del comportamiento de suelos cohesivos cargados cíclicamente que se deberían tener en cuenta para el desarrollo de nuevos modelos constitutivos usados en la predicción del comportamiento de estos suelos.

Palabras clave: suelos cohesivos; cargas cíclicas; comportamiento post-cíclico.

\section{ABSTRACT}

The response of cohesive soils subjected to cyclic loading is affected by different factors; the most important are soil type, stress or consolidation history, and specific test conditions. To better understand the behavior of cohesive soils subjected to cyclic loading, beginning in early 1960's,

1. Department of Civil Engineering, Universidad Militar Nueva Granada, Bogotá, Colombia, andres.nieto@unimilitar.edu.co

2. Department of Civil and Environmental Engineering, University of Delaware, U.S.A, kaliakin@udel.edu 
a rather substantial body of experimental work has been performed. This has involved different types of soils, tested at different values of overconsolidation ratio, and subjected to different cyclic loading histories. This paper compiles the most important findings of the aforementioned experimental work on cohesive soils. It summarizes the general behavioral trends observed for cyclically loaded cohesive soils. Besides, several key characteristics of cyclically loaded cohesive soils that any rational mathematical simulation must account for have been identified, thus offering the general trends that should be taken into account in the development of new constitutive models used in predicting the response of such soils.

Keywords: cohesive soils; cyclic loading; post-cyclic response.

\section{INTRODUCTION}

To better understand the behavior of cohesive soils subjected to cyclic loading, beginning in the early 1960's, a rather substantial body of experimental work has been performed. This has involved different types of soils, tested at different overconsolidation ratios (OCRs), and subjected to different cyclic loading histories.

Based on the findings of the aforementioned experimental work, the response of cohesive soils subjected to cyclic loading is known to be affected by different factors. The most important of these factors are the soil type, the stress or consolidation history, and the specific test conditions. The type of soil is commonly quantified by the value of the plasticity index (Ip).

Regarding the consolidation history, normally consolidated and overconsolidated clays respond differently to cyclic loading. When subjected to cyclic loading, normally consolidated cohesive soils exhibit an apparent overconsolidation and tend to be more resistant to undrained cyclic loading than overconsolidated ones. This conclusion has been established by a subset of investigators [1-8] that tested cohesive soils over a rather large range of OCRs that spanned from 1 to 50 . In addition, anisotropically consolidated soils are known to behave differently from ones that are consolidated isotropically.

The loading conditions imposed in a given cyclic test on a cohesive soil affect its response. In particular, the cyclic response of such soils depends on the frequency and type of cyclic loading, as well as on the cyclic stress level (or cyclic strain amplitude). Cyclic loading is generally applied under either stress- or straincontrolled conditions. In many past cyclic tests, the loading was applied at frequencies ranging between 0.1 and $0.5 \mathrm{~Hz}$. However, in order to obtain reliable excess pore pressure measurements during undrained cyclic loading, very low axial strain rates (e.g., $0.0002 \% / \mathrm{min}$ [9] and $0.4 \% / \mathrm{hr}$ [7]) and low frequencies (e.g., $0.001 \mathrm{~Hz}[10,11])$ have been used.

The tests that are used the most to evaluate the cyclic response of cohesive soils are the axisymmetric triaxial test with constant radial stress (constant confining pressure) and the direct siple shear test. Cyclic loading has been applied in either one-way (non-reversal) or two-way (full reversal) conditions. In the former case, only compressive deviator stresses in 
the axisymmetric triaxial test or positive shear stresses in the direct simple shear test are applied [2, 4, 8, 12-28]. In the latter case, twoway or reversed loading, consisting of positive (compressive) and negative (extensional) stresses, is applied to the sample. Two-way loading is typically applied more quickly than, and tends to disturb a sample more than one-way loading [1, 5, 29-45]. There are also instances where both one and two-way loading have been used in a given testing program [3, 46-51]. Finally, irregular [52], harmonic [53], and "storm" [6,54] loading have also been applied.

Although, the majority of the experimental investigations were undertaken to study the strength of cohesive soils under cyclic loading, some also focused on the degradation of elastic shear modulus $(G)$ and on the damping ratio due to cyclic loading $[34,36,55]$.

Finally, some investigations have been undertaken to better understand the postcyclic behavior of cohesive soils. These included a study of consolidation due to the dissipation of excess pore pressure developed during cyclic loading (in such cases a drainage period is imposed following an undrained cyclic event so as to allow for the dissipation of excess pore pressure.) $[5,6,40,47,54]$, and the postcyclic strength under monotonic undrained axisymmetric triaxial $[2-4,15,20,23,30,31$, $43,50,51,56]$, direct simple shear [35], and monotonic torsional [57] loading.

Due to the vast amount of experimental work, this paper compiles the most important findings of the aforementioned experimental work on cohesive soils. It significantly expands the previous review of this subject presented by Lee and Focht [58], and summarizes the general behavioral trends observed for cyclically loaded cohesive soils. It is important to mention that the general trends given in this work have been evaluated from a widely experimental work under different test conditions; however, a reasonable interpretation of the experimental data resulted in such general behavioral trends observed in the response of cohesive soils. In addition, this review identifies several key characteristics of cyclically loaded cohesive soils that any rational mathematical simulation must account for. These, in turn, serve as guidelines for the development of constitutive models for predicting the response of cohesive soils under cyclic and earthquake loading.

\section{EXPERIMENTAL RESPONSE OF COHESIVE SOILS SUBJECTED TO CYCLIC LOADING}

This section compiles the most important findings of the experimental studies on cohesive soils that were summarized in the previous section. Nieto-Leal and Kaliakin [59] present a more thorough, though less synthesized compilation of the results of cyclic tests performed on cohesive soils.

\subsection{Cyclic thresholds}

In one of the earliest experimental research of the cyclic response of cohesive soils, Larew and Leonards [60] observed the existence of limiting cyclic stress values for compacted soil samples. For stress levels below such a limit, a cyclically loaded sample does not accumulate inelastic strain, nor does it suffer any degradation in stiffness. In addition, under undrained conditions, no excess pore pressure is accumulated. In short, the sample essentially exhibits elastic response. If the cyclic stress 
amplitude exceeds the aforementioned limiting value, the sample exhibits inelastic response, possibly leading to failure.

Figure 1 illustrates the response for cyclic deviator stress $\left(q_{c v c}\right)$ levels below and above the limiting value. Both cases involve nonreversal cyclic loading under undrained conditions. For $q_{c y c}=180 \mathrm{kPa}$, the deviator stress level is below the limiting one; it is evident that the sample reaches an equilibrium state that is characterized by negligible hysteresis and inelastic strain (Figure 1a) and very small excess pore pressure $(\Delta u)$ increases (Figure 1b). Although 80 load cycles were applied to it, the sample did not fail. However, once $q_{c y c}$ was increased to $290 \mathrm{kPa}$, the sample exhibited inelastic response, replete with appreciable inelastic strains and increased excess pore pressure.

Several researchers $[3,8,9,12,16,19,20$, $26,42,50,61,62]$ subsequently confirmed the existence of limiting cyclic stresses, which were typically referred to as "threshold cyclic stresses." It was also determined that, for the same soil, the threshold cyclic stress level increases with $O C R$ [3]. For normally consolidated, as well as overconsolidated samples, the threshold stress level was found to be about two-thirds of the maximum undrained shear strength as determined in a monotonic load test [9]. This finding holds for both isotropically and anisotropically consolidated samples.

At high cyclic stress levels, after a certain number of cycles, the residual strain accelerates towards failure. This trend has been observed in both undisturbed and remolded cohesive soils $[19,57]$.

In cemented cohesive soils, the threshold condition is governed by the cementation strength $[24,25]$. Consequently, cementation bonds significantly influence the response. At sufficiently high cyclic stress levels, such bonds are broken, leading to the development of inelastic strains and excess pore pressure.

The limiting cyclic response can also be defined by the amplitude of the cyclic shear strain.
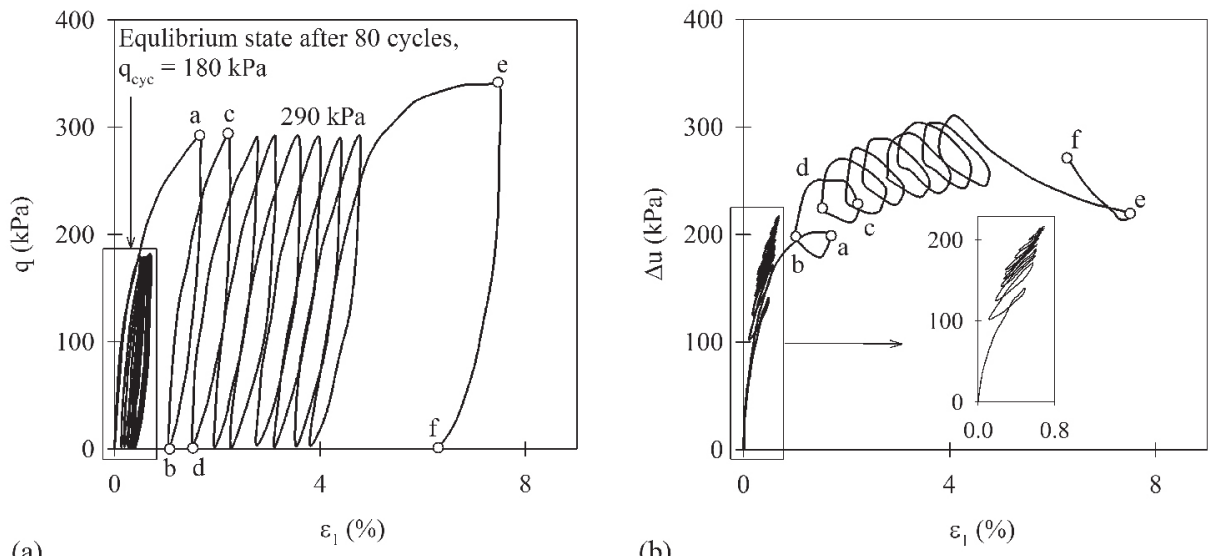

Figure1. Deviator stress and pore pressure evolution for $q_{c y c}=180 \mathrm{kPa}$ and 290kPa [12]. 
Thus, if the cyclic strain is less than some threshold value, only negligible inelastic strains will accumulate and excess pore pressure will increase, even with a large number of loading cycles $[5,8,63,64]$. In general, the threshold cyclic strain tends to increase with plasticity index, albeit sometimes only marginally. Specific values defining the strain threshold limits are clearly dependent on the type of soil. More recently, different limits or thresholds have been proposed based on specific soil response [27, 45, 52, 65-67]. For example, the "elastic threshold" corresponds to small cyclic strain amplitudes [52]. Below this threshold (i.e., the small strain region), the degradation of the dynamic and post-cyclic engineering properties would be expected to be negligible. Once the elastic threshold is exceeded, however, the induced cyclic shear strain increases and the material tends to exhibit strain softening, stiffness degradation, inelastic strain accumulation, and increases in excess pore pressure. This response continues up to the so-called "plastic threshold". If this limit is exceeded, the soil will attain large strain amplitudes due to the accumulation of inelastic strains and to stiffness degradation. The final strain level is referred to as the "flow threshold"; at this level the soil has reached a steady state condition and behaves as a viscoplastic material up to failure. In concluding this section, it is timely to note that in a relatively few cases the presence of a cyclic threshold stress was either not fully realized $[7,68]$ or not realized at all [2].

\subsection{Effect of loading conditions}

In terms of loading conditions, both excess pore pressure and inelastic strain develop more rapidly under two-way (reversal) cyclic loading than under one-way (non-reversal) loading. As shown in Figure 2a [47], the cyclic strength under two-way loading is slightly smaller than for one-way loading. In addition, the amount of stiffness degradation is higher for the case of two-way loading.

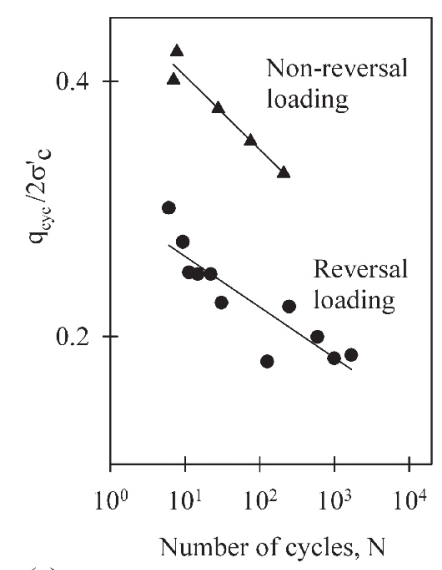

(a)

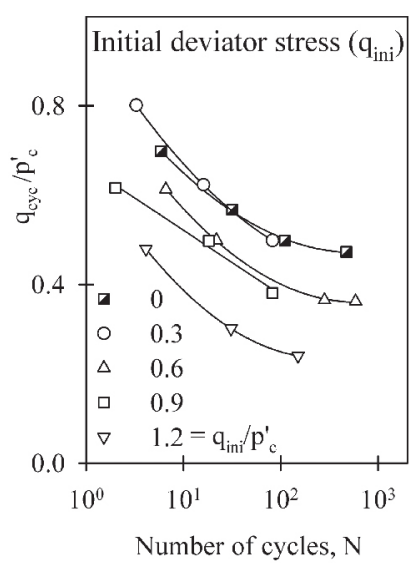

(b)

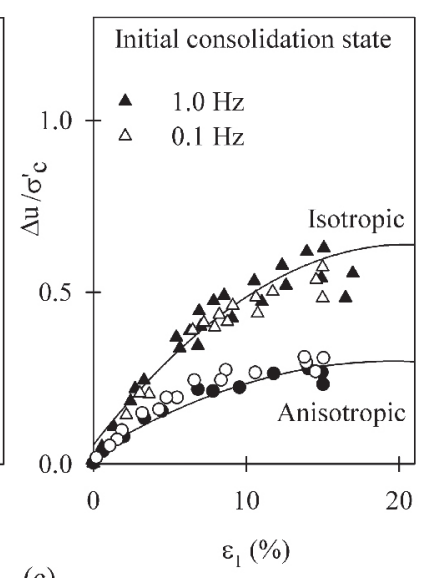

(c)

Figure 2. Cyclic response under different loading conditions and consolidation states. 
The effect of the magnitude of the initial deviator stress (or shear stress in direct simple shear tests) on the cyclic response has been rather well-studied [14, 21, 38, 41, 45, $46,48,49,51,69,70]$. The higher the initial deviator stress (i.e., the higher the initial degree of anisotropy), the fewer the number of cycles that are required to reach failure, and the lower the cyclic strength (Figure 2b). In addition, due to the fact that in some cases the reversal condition disappears for high levels of initial deviator stress, the rate of stiffness degradation in anisotropically consolidated soils is lower than for isotropically consolidated ones [70]. In the latter case, any cyclic deviator stress magnitude will involve reversed loading, thus accelerating the rate of stiffness degradation. Finally, as shown in Figure 2c, isotropically consolidated samples tend to develop higher excess pore pressures as compared to anisotropically consolidated ones [17].

\subsection{Effect of loading frequency}

In general, loading frequency effects tend to diminish with increasing number of cycles and with decreasing cyclic deviator stress amplitude. The influence of frequency appears to be significant if relatively small numbers of cycles are considered. When loaded at high frequencies, cohesive soils exhibit higher cyclic shear strength than when loaded at lower frequencies. This is consistent with the rate-dependent response of cohesive soils in which shear strength increases with increased loading rates.

For a given number of cycles, larger shear strains and excess pore pressures are typically generated at lower frequencies $[8,14,15,19$, $21,28,32,41,71-73$ ]. Lefebvre et al. [62] found that increasing the frequency from 0.01 to 2.0 $\mathrm{Hz}$ will result in an increase of the threshold cyclic stress for structured and normally consolidated clays. It is also appropriate to mention that at very low frequencies the excess pore pressure generated during cyclic loading has been shown [74] to consist of a portion that is due to purely cyclic loading, and one that is attributed to undrained creep.

\subsection{Effect of drainage period}

Cyclic tests have been performed on normally consolidated [6, 44] and overconsolidated samples [54] so as to investigate the recompression or settlement of cohesive soils following consecutive cyclic loading events. In such tests, undrained cyclic events were separated by periods of time to allow for the dissipation of excess pore pressure under drained conditions.

Results from such "partially drained" tests on normally consolidated samples indicate that the excess pore pressure decreases for each cyclic loading event (Figure 3a). During the subsequent periods of pore pressure dissipation, the void ratio continuously decreases. Tests performed on overconsolidated samples showed opposite tendencies. In particular, the excess pore pressure increases during each loading event (Figure 3b); during the subsequent dissipation phases, the void ratio increases. Thus, cyclic loading events followed by periods of drainage can have a detrimental effect on the response of overconsolidated soils since they will have lower resistance to subsequent undrained cyclic loading events.

A rather limited number of "partially drained" tests have been performed $[13,18,26,40]$ to 
investigate the volumetric strains generated during cyclic loading. In normally consolidated samples, the dissipation of excess positive pore pressure leads to a decrease in water content and void ratio after each cycle. This, in turn, results in an increase in the shear strength. By contrast, the partially drained loading of overconsolidated samples is characterized by negative residual excess pore pressures that remain after the first undrained load-unload cycle. Thus, under drained conditions water is drawn into such samples. The process continues for subsequent loading cycles, though a smaller negative residual pore pressure is developed with each subsequent cycle. Nonetheless, if cyclic loading continues, an overconsolidated sample will draw in sufficient water as to reduce its shear strength. Finally, as compared to samples tested under fully undrained conditions, partially drained ones require a greater number of cycles and higher deviator stress levels to reach failure.

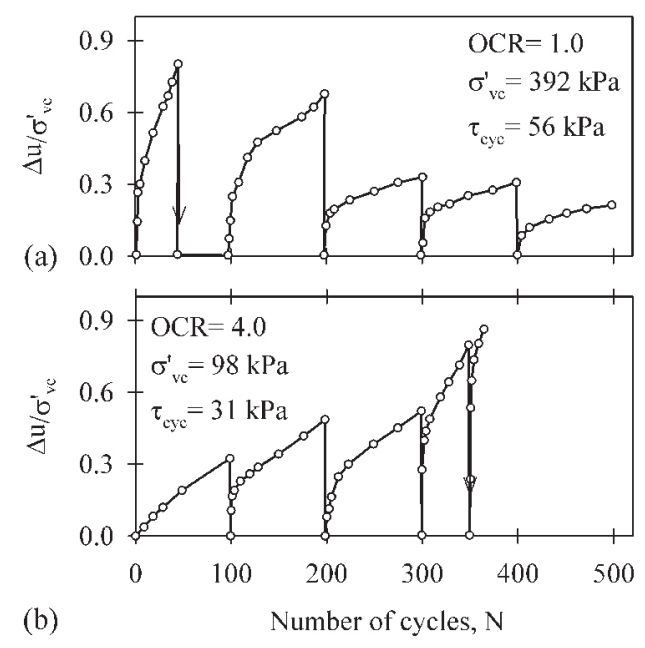

Figure 3. Pore water pressure during cyclic loading with drainage periods [6-54].

\subsection{Undrained stress paths}

In cyclically loaded and normally consolidated samples tested under undrained conditions, the effective stress paths migrate towards the origin of the stress space. The net associated pore pressure will thus be increasingly positive. Since the material continues to harden, the soil undergoes an apparent overconsolidation similar to that exhibited by normally consolidated cohesive soils during undrained creep.

In cyclically loaded overconsolidated samples, the effective stress path tends to initially proceed away from the stress origin; subsequently, however, it reverses its direction towards the origin. Figure 4 shows how the effective mean stress $(p)$ first increases and then decreases for overconsolidated samples. Although the development of axial strain accelerates for overconsolidated samples, the rate of excess pore pressure development progressively diminishes.

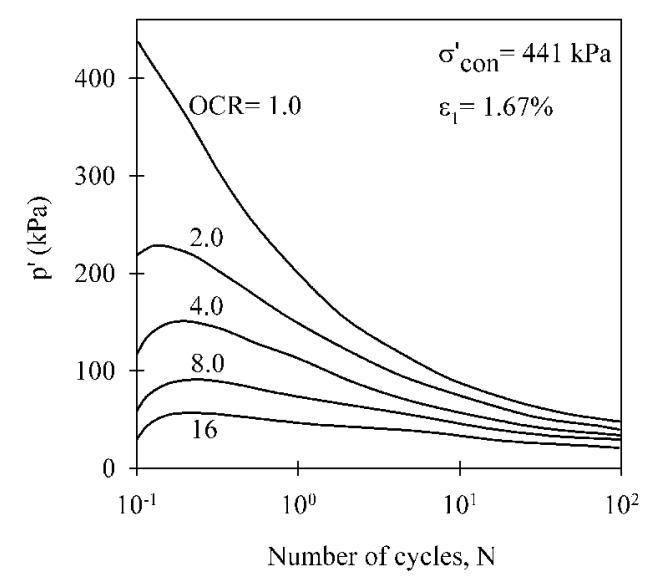

Figure 4. Decrease in mean effective principal stress during cyclic test [1]. 
The rate of migration of the effective stress path towards the stress origin depends on the cyclic stress/strain magnitude, the consolidation history, and on the frequency of loading. In particular, normally consolidated samples migrate faster than overconsolidated ones. Samples loaded at low frequencies generate higher pore pressures; their migration towards the stress origin is thus more rapid than for ones loaded at higher frequencies $[1,5,10]$.

\subsection{Pore pressure response}

Closely related to the issue of undrained stress paths is the generation of excess pore pressure during undrained cyclic loading. As noted in the previous section, loading of normally consolidated samples generates positive excess pore pressure. Upon unloading, the excess pore pressure would be expected to continuously reduce in magnitude. Certain experimental results do not, however, show this to always be the case. For example, Sangrey [9] performed one-way (nonreversal) cyclic tests on undisturbed samples of Newfield clay $(I p=10)$. To ensure equalization of the excess pore pressure, an axial strain rate of approximately $0.0002 \%$ per minute was used (each loading-unloading cycle was thus approximately 10 hours in duration). Sangrey [9] found that during the unloading phase the excess pore pressure initially decreased. This trend reversed itself rather quickly, however, as the excess pore pressure again became positive (Figure 1b). This pore pressure response will occur provided the magnitude of the cyclic deviator stress $\left(q_{c y c}\right)$ exceeds the threshold stress.

In a related experimental program, Sheu [11] performed one-way (non-reversal) cyclic tests on reconstituted samples of Georgia kaolin clay $(I p=20)$ with cyclic stress levels above the threshold cyclic stress. To ensure equalization in excess pore pressure, a loading frequency of $0.001 \mathrm{~Hz}$ was used in these tests. Depending on the cyclic deviator stress level, three different types of response were noted. For relatively low values of $q_{c y c}$ the excess pore pressure generated during loading differed in magnitude and sign from that generated during unloading (Figure 5a). For higher levels of $q_{c y c}$ this response changed. Now, the excess pore pressure first decreased but then increased during unloading (Figure 5b). Finally, for even higher levels of $q_{c y c}$ the excess pore pressure increased more significantly during unloading (Figure 5c). As pointed out by Sheu [11], such pore pressure response significantly complicates the mathematical modeling and numerical simulation of cohesive soils subjected to cyclic loading.

By contrast, if $q_{c y c}$ is less than the threshold, the excess pore pressure increases during loading (i.e., during increases in $q_{c y c}$ ) and decreases upon unloading $[9,11]$. An equilibrium state is thus reached [59]. Figure 1b shows the response of one sample that was loaded to $q_{\text {cyc }}$ levels below the threshold value. With an increasing number of loading cycles, the excess pore pressure is seen to increase upon loading and to then decrease upon unloading. The resulting deviator stress-strain loops are essentially closed (recall Figure 1a), indicating very little hysteresis and thus largely elastic response.

In closing this section it is timely to note that the aforementioned excess pore pressure response was observed for samples that were loaded very slowly. It is thus quite likely that time effects contribute to this response [74]. Since the total stress varies during both the loading and unloading phases of a cyclic test, 


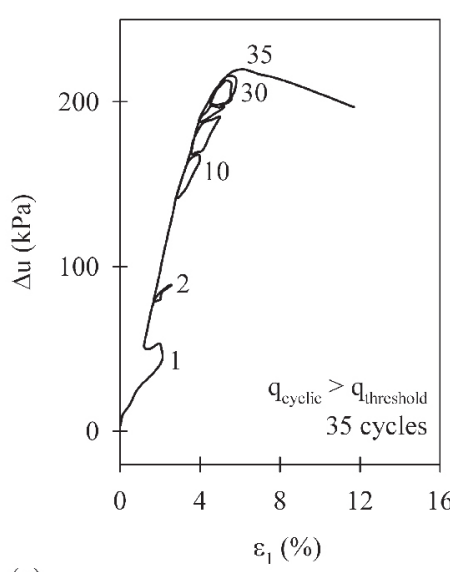

(a)

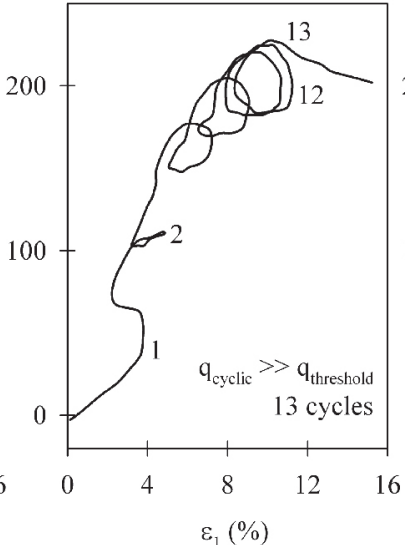

(b)

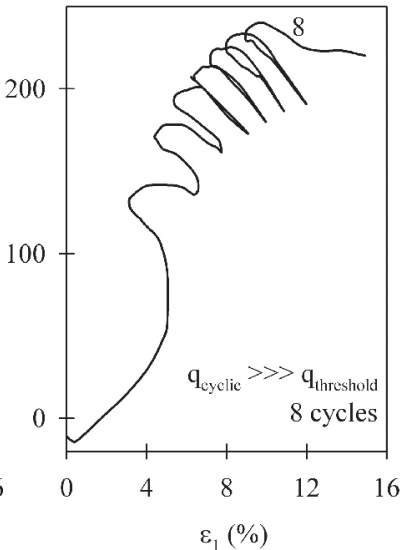

(c)

Figure 5. Stress-strain-pore pressure with $q_{c y c}$ above the qThreshold [11]

truly creep conditions are not maintained. In addition, since the test specimens deform almost continually, truly relaxation conditions are likewise not maintained. The time-related response is thus general in nature. It follows that such response will therefore affect the cyclic response, especially for low frequency loading, and should thus be accounted for in constitutive models developed to simulate such response in cohesive soils.

\subsection{Stiffness degradation}

Cyclically loaded cohesive soils may exhibit stiffness degradation $[8,14,29,30,34,36$, $75,76]$. This characteristic is rather strongly dependent on the level of cyclic stress/ strain applied to the sample. Cyclic loading that induces large strains tends to produce appreciable stiffness degradation. In general, substantial degradation typically occurs during the first few loading cycles.

Degradation of the elastic shear modulus has been quantified using the so-called "degradation index" $d=G_{s N} / G_{s 1^{\prime}}$ where $G_{s N}$ and $G_{s 1}$ are the secant shear modulus after $\mathrm{N}$ cycles and first cycle at constant shear strain amplitude, respectively [34]. Small d values correspond to high degrees of stiffness degradation. As seen from Figure 6, d tends to be lower for normally consolidated samples than for overconsolidated ones. Thus, $G$ degrades more and faster for normally consolidated samples. In addition, the controlled cyclic shear strain amplitude $\left(g_{c}\right)$ increases with OCR (Figure 6).

For both normally and overconsolidated samples, $G$ decreases with increasing numbers of cycles. In addition, the higher the deviator cyclic stress level, the more pronounced the decrease in $G$ will be.

In overconsolidated samples, Zapata-Medina et al. [77] found that the stress history may affect the strain accumulation mechanism observed during cyclic triaxial tests. If tested at low cyclic shear stress levels, samples that were isotropically consolidated exhibited linear and perfectly elastic response with neither 
energy dissipation nor permanent deformation after unloading in the first compression cycle. By contrast, the response of anisotropically consolidated samples was nonlinear with permanent strains [77].

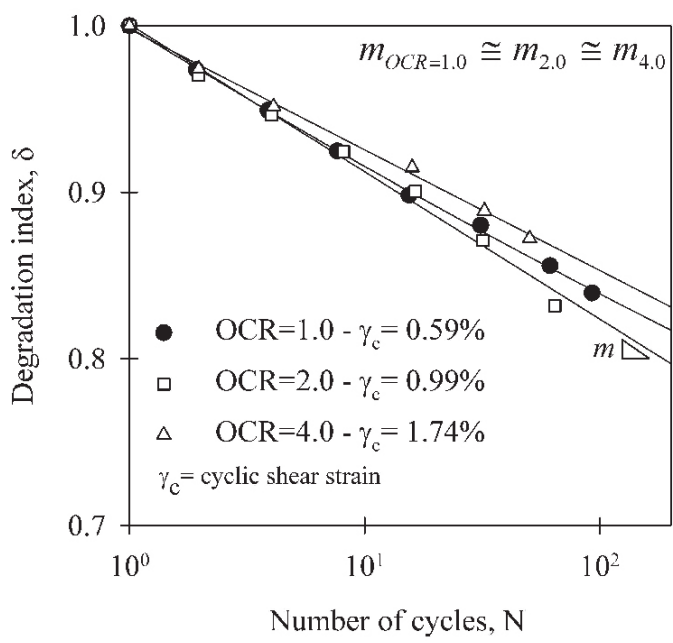

Figure 6. Degradation index versus number of cycles for different OCR values [34].

\subsection{Role of the plasticity index}

The plasticity index (Ip) appears to be a key indicator of the response of cohesive soils subjected to cyclic loading. In particular, as Ip increases from non-plastic (NP) to highly plastic soils, the cyclic shear strength likewise increases (Figure 7). Micromechanically, this is explained by the fact that clays with higher I $p$ values have larger values of specific surface (i.e., the ratio of the surface area per mass of dry soil particles). Such clays thus have a greater potential for attracting neighboring particles, and typically form particle clusters. This, in turn, increases the resistance of the clay to cyclic loading.

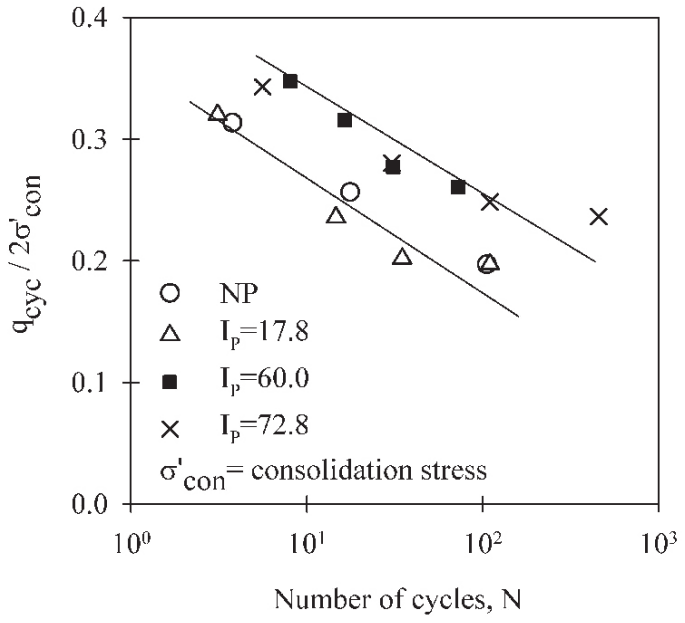

Figure 7. Effect of plasticity index on cyclic strength in normally consolidated clays [69].

The threshold or critical strain level tends to increase with Ip [62-63]. In addition, experimental results $[42,52,53,55,57,69,73]$ confirm the fact that the $I p$ is one of the key indicators of the degradation of dynamic shear modulus during cyclic loading (recall the discussion of Section 1.7). Finally, it is relevant to note that the relationship between plasticity and cyclic response has been found to be independent of the pore fluid chemistry in fine-grained soils [78].

\subsection{Post-Cyclic response}

As evident from the previous section, a rather substantial body of experimental work has been performed on cyclically loaded cohesive soils. Perhaps of equal importance, though not nearly as extensively studied, is the postcyclic response of such soils. Post-cyclic tests generally consist of standard monotonic 
loading that is applied to samples after completion of the cyclic loading.

As noted in Section 1.5, normally consolidated samples subjected to undrained cyclic loading exhibit an apparent overconsolidation. The level of such overconsolidation increases with continued cyclic loading. Since this is accompanied by increases in the excess pore pressu$\mathrm{re}$, the effective stress state is progressively reduced. It follows that if monotonic loading is applied following a cyclic loading event, the sample will respond similar to an overconsolidated one $[1,3,4,16,23,29,35,43,47,79]$. Figure 8 illustrates the fact that stress paths associated with monotonic loading applied after cyclic loading are typical of those observed for overconsolidated samples.

The undrained shear strength of cohesive soils tends to decrease for larger induced cyclic strain amplitudes. Since stiffness degradation is rather strongly dependent on the level of cyclic stress/strain applied to the sample (recall the discussion of Section 1.7), it follows that the more degradation

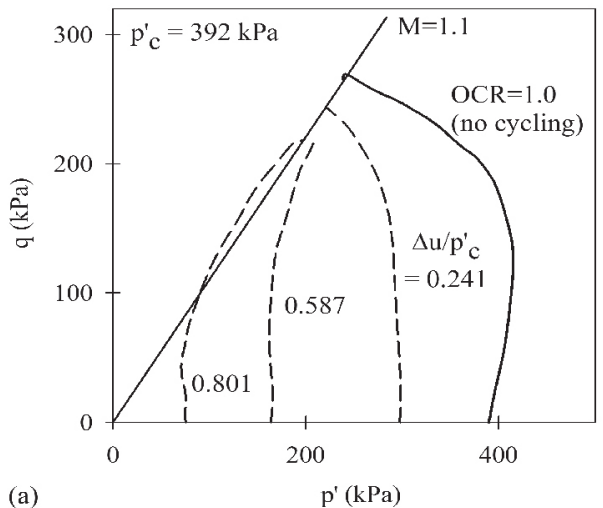

that a sample exhibits, the greater will be the reduction in post-cyclic shear strength. It is opportune to note that both stiffness degradation during cyclic loading and the post-cyclic response are directly affected by the magnitude of the induced cyclic shear strain, rather than by the cyclic stress level. If the strain is below the threshold value, the reduction in post-cyclic shear strength will be small or altogether nil [62]. If, on the other hand, the induced cyclic strain exceeds the threshold value, the reduction in post-cyclic shear strength will be quite significant. Finally, since cyclically loaded overconsolidated samples do not generate large positive excess pore pressures, it follows that the reduction in their shear strength will be smaller than for normally consolidated samples.

Figure 9 illustrates the effect that drainage prior to post-cyclic loading has on the undrained shear strength. Comparing first the post-cyclic response without drainage to the monotonic case, it is evident that the elastic modulus decreases significantly more than the shear strength. Many researchers $[1,3,4,7$,

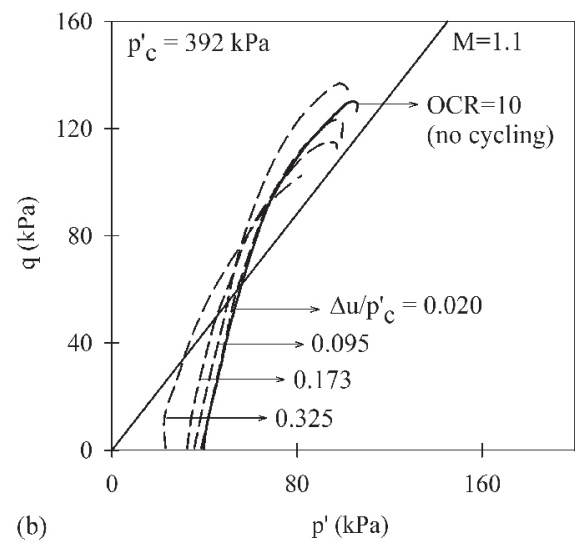

Figure 8. Effective stress paths corresponding to post-cyclic events [43] 
$20,29-31,42,47,57,68,75,79,80,81]$ have confirmed such behavior.

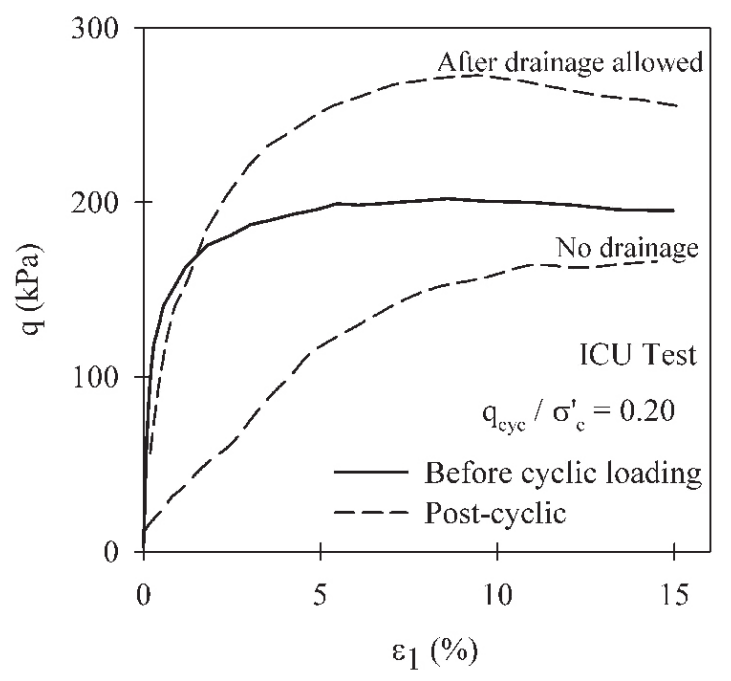

Figure 9. Postcyclic response of cohesive soils and secant Young modulus [47].

For example, Yasuhara et al. [43] found that the post-cyclic undrained shear strength was not less than $20 \%$ of the value associated with monotonic loading. The degradation in stiffness (or elastic modulus) was, however, quite remarkable [45-56]. Yasuhara et al. [43] thus concluded that cyclic softening, which sometimes triggers lateral deformation and instability in fine-grained plastic silty soils during earthquakes, could be caused by a decrease in stiffness rather than by a reduction in undrained shear strength. Indeed, the effective shear strength parameters $c^{\prime}$ (cohesion) and $\phi^{\prime}$ (internal friction angle) appear to be unaffected by cyclic loading [3, 28, 82].

From Figure 9 it is evident that, in the case of post-cyclic response with drainage allowed, the reduction in void ratio that accompanies the drainage manifests itself in volumetric hardening and a rather substantial increase in shear strength $[16,47,51,83,84]$.

\section{CONCLUSIONS}

Having discussed the main findings of past experimental investigations of the response of cyclically loaded cohesive soils, it is timely to summarize some general trends that have been observed.

There is a critical cyclic stress or strain that is sometimes referred to as the "cyclic threshold". This threshold clearly delineates two distinct types of response. For cyclic stress/strain amplitudes below the threshold, a sample reaches an equilibrium state. If, on the other hand, the cyclic stress/strain amplitude exceeds the threshold, a sample will accumulate inelastic strains, will generate excess pore pressure and may fail. For cohesive soils that are initially at the same state of effective stress but at different overconsolidation ratios, the threshold stress will increase with overconsolidation ratio.

Cyclic loading causes an apparent overconsolidation of normally consolidated samples due to the reduction in the effective stress during cyclic loading. As the overconsolidation ratio increases, this apparent overconsolidation is less noticeable.

Undrained cyclic loading causes a build-up of positive excess pore pressures in normally consolidated specimens. By contrast, in overconsolidated specimens a negative pore pressure may develop in the early cycles. With continued cyclic shearing, the generation of negative excess pore pressure slowly decreases; the excess pore pressure may thus 
start to increase and may eventually become positive. The higher the overconsolidation ratio, the more resistancethere is against subsequent positive excess pore pressure generation with cyclic loading. Thus, cyclic strength increases, and the soil stiffness degradation decreases with increasing overconsolidation ratio.

Since cohesive forces increase in higher plasticity clays, such soils develop lower amounts of cyclic shear strain as compared to lower plasticity silts and clays. Cyclic strength thus increases with plasticity index.

The rate at which the effective stress path migrates towards the origin in stress space, and hence the rate at which stiffness degrades, depends on the cyclic stress level applied to a sample, the consolidation history, and the frequency of loading. Increasing the cyclic stress level increases the rate of migration of the effective stress cycles. Normally consolidated samples migrate faster than overconsolidated ones. Samples loaded at low frequencies generate higher excess pore pressures and thus migrate more rapidly than ones loaded at higher frequencies. Low frequency loading leads to the lowest cyclic strength and to higher amounts of stiffness degradation. Reversal cyclic loading has a more damaging effect on cohesive soils than non-reversal cyclic loading.

In general, post-cyclic undrained shear strength is not less than approximately $25 \%$ of the initial or pre-cyclic undrained shear strength. The strength decrease becomes larger with increasing cyclic shear strain level and with an increase in the number of cycles.

When the induced cyclic shear strain amplitude is less than the threshold cyclic strain, no significant stiffness degradation will occur; the reduction in post-cyclic strength will therefore be negligible. Since cyclic loading leads to softening of a sample, the decrease of the undrained modulus during monotonic loading following cyclic loading is larger than the decrease of strength.

Although some authors report that post-cyclic undrained shear strength is independent of the overconsolidation ratio, others have found that the reduction in strength after cyclic loading is greater for normally consolidated and lightly overconsolidated samples than for heavily overconsolidated ones.

\section{ACKNOWLEDGEMENT}

The first author's graduate studies are supported by the Fulbright ColombiaColciencias Scholarship and Universidad Militar Nueva Granada. This support is gratefully acknowledged.

\section{REFERENCES}

[1] Taylor, P.W. and Bacchus, D.R. (1969). Dynamic cyclic strain tests on a clay. In Proceedings of 7 th International Conference on Soil Mechanics and Foundation Engineering, 1, pp. 401-409.

[2] Brown, S.F., Lashine, A.K.F., and Hyde, A.F.L. (1975). Repeated load triaxial testing of a silty clay. Géotechnique, 25(1), pp. 95-114. doi: 10.1680/ geot.1975.25.1.95.

[3] Andersen, K.H., Pool, J.H., Brown, S.F., and Rosen-Brand, W.F. (1980). Cyclic and static laboratory tests on Drammen clay. Journal of Geotechnical Engineering Division, 106(GT5), pp. 499-529. 
[4] Hyde, A.F.L. and Ward, S.J. (1986). The effect of cyclic loading on the undrained shear strength of a silty clay. Marine Geotechnology, 6(3), pp. 299-314. doi: 10.1080/10641198609388192.

[5] Ohara, S. and Matsuda, H. (1988). Study on the settlement of saturated clay layer induced by cyclic shear. Soils and Foundations, 28(3), pp. 103-113. doi: 10.3208/sandf1972.28.3_103.

[6] Yasuhara, K. and Andersen, K.H. (1989). Effect of cyclic loading on recompression of overconsolidated clay. In Proceedings of the 12th International Conference on Soil Mechanics and Foundation Engineering, 1, pp. 485-488.

[7] Zergoun, M. (1991). Effective stress response of clay to undrained cyclic loading. (PhD thesis). University of British Columbia, Canada.

[8] Zhou, J. and Gong, X. (2001). Strain degradation of saturated clay under cyclic loading. Canadian Geotechnical Journal, 38, pp. 208-212. doi: 10.1139/ t00-062.

[9] Sangrey, D.A. (1968). The behaviour of soils subjected to repeated loading. (PhD thesis). Cornell University, U.S.A.

[10] Takahashi, M., Hight, D.W., and Vaughan, P.R. (1980). Effective stress changes observed during undrained cyclic triaxial tests on clay. In International Symposium on Soils under Cyclic and Transient Loading, 1, pp. 201-209.

[11] Sheu, W.A. (1984). Modelling of stress strain strength behavior of a clay under cyclic loading. (PhD thesis). University of Colorado, U.S.A.

[12] Sangrey, D.A., Henkel, D.J., and Esrig, M.I. (1969). The effective stress response of a saturated clay soil to repeated loading. Canadian Geotechnical Journal, 6(3), pp. 241-252. doi: 10.1139/t69-027.

[13] France, J.W. and Sangrey, D.A. (1977). Effects of drainage in repeated loading of clays. Journal of the Geotechnical Engineering Division, 103 (GT7), pp. 769-785.

[14] Ishihara, K. and Yasuda, S. (1980). Cyclic strengths of undisturbed cohesive soils of western Tokyo. In Internatioal Symposium on Soils under Cyclic and Transient Loading, pp. 57-66.

[15] Matsui, T., Ohara, H., and Ito, T. (1980). Cyclic stress strain history and shear characteristics of clay. Journal of the geotechnical Engineering Division, 106 (GT10), pp. 1101-1120.

[16] Meimon, Y. and Hicher, P.Y. (1980). Mechanical behaviour of clays under cyclic loading. In International Symposium on Soils under Cyclic and Transient Loading, pp. 77-87.

[17] Yasuhara, K., Yamanouchi, T., and Hirao, K. (1982). Cyclic strength and deformation of normally consolidated clay. Soils and Foundations, 22(3), pp. 77-91. doi: 10.3208/sandf1972.22.3_77.

[18] Hyodo, M., Yasuhara, K., Murata, H., and Hirao, K. (1988). Behaviour of soft clay deposit subjected to long-term cyclic shear stresses. Technical Report in Yamaguchi University, pp. 171-181. 
[19] Ansal, A.M. and Erken, A. (1989). Undrained behavior of clay under cyclic shear stresses. Journal of Geotechnical Engineering, 115 (7), pp. 968-983.

[20] Díaz-Rodríguez, A. (1989). Behavior of Mexico City clay subjected to undrained repeated loading. Canadian Geotechnical Journal, 26, pp. 159-162. doi: 10.1139/ t89-016.

[21] Konrad, J.M. and Wagg, B.T. (1993). Undrained cyclic loading of anisotropically consolidated clayey silts. Journal of Geotechnical Engineering, 119 (5), pp. 929949.

[22] McCarron, W. O., Lawrence, J. C., Werner, R. J., Germaine, J.T., and Cauble, J. T. (1995). Cyclic direct simple shear testing of a Beaufort Sea clay. Canadian Geotechnical Journal, 32, pp. 584-600.

[23] Yasuhara, K. (1997). Effect of initial static shear stress on post cyclic degradation of plastic silt. In Proceedings of the 13th International Conference on Soil Mechanics and Foundation Engineering, pp. 1-4.

[24] Moses, G.G., Rao, S.N., and Rao, P.N. (2003). Undrained strength behavior of a cemented marine clay under monotonic and cyclic loading. Ocean Engineering, 30, pp. 1765-1789.

[25] Moses, G.G. and Rao, S.N. (2007). Behavior of marine clay subjected to cyclic loading with sustained shear stress. Marine Georesources and Geotechnology, 25(2), pp. 81-96.

[26] Hanna, A.M. and Javed, K. (2008). Design of foundations on sensitive Champlayn clay subjected to cyclic loading. Journal of Geotechnical and Environmental Engineering, 134(7), pp. 929-937.

[27] Tang, Y.Q., Zhou, J., and Liu, S. (2011). Test on cyclic creep behavior of Mucky clay in Shangay under step cyclic loading. Environmental Earth Sciences, 63, pp. 321327.

[28] Li, L.L., Dan, H.B., and Wang, L.Z. (2011). Undrained behavior of natural marine clay under cyclic loading. Ocean Engineering, 38 (16), pp. 1792-1805.

[29] Thiers, G.R. and Seed, H.B. (1968). Cyclic stress strain characteristics of clay. Soil Mechanics and Foundations Division, 94 (SM2), pp. 555-569.

[30] Idriss, I.M., Dobry, R., and Singh, R. (1978). Nonlinear behavior of soft clays during cyclic loading. Journal of the Geotechnical Engineering Division, ASCE, 104(GT12), pp. 1427-1448.

[31] Koutsoftas, D.C. (1978). Effect of cyclic loads on undrained strength of two marine clays. Journal of Geotechnical Engineering, ASCE, 104(GT5), pp. 609620.

[32] Procter, D.C. and Khaffaf, J.H. (1984). Cyclic triaxial tests on remolded clays. Journal of Geotechnical Engineering, 110(10), pp. 1431-1445.

[33] Fujiwara, H., Ue, S., and Yasuhara, K. (1987). Secondary compression of clay under repeated loading. Soils and Foundations, 27(2), pp. 21-30. doi: 10.3208/sandf1972.27.2_21. 
[34] Vucetic, M. and Dobry, R. (1988). Degradation of marine clays under cyclic loading. Journal of Geotechnical Engineering,114(2), pp. 133-149.

[35] Azzouz, A.S., Malek, A.M., and Baligh, M.M. (1989). Cyclic behavior of clays in undrained simple shear. Journal of Geotechnical Engineering, 115(5), pp. 637-657. doi: 10.1061/(ASCE)07339410(1989)115:5(637).

[36] Vucetic, M. (1990). Normalized behavior of clay under irregular cyclic loading. Canadian Geotechnical Journal, 27(1), pp. 29-46. doi: 10.1139/t90-004.

[37] Hirao, K. and Yasuhara, K. (1991). Cyclic strength of underconsolidated clay. Soils and Foundations, 31(4), pp. 180-186.

[38] O'Reilly, M.P., Brown, S.F., and Overy, R.F. (1991). Cyclic loading of silty clay with drainage periods. Journal of Geotechnical Engineering, 117(2), pp. 354-362. doi: 10.1061/(ASCE)07339410(1991)117:2(354).

[39] Cao, Y.L. and Law, K.T. (1992). Energy dissipation and dynamic behaviour of clay under cyclic loading. Canadian Geotechnical Journal, 29(1), pp. 103-111. doi: 10.1139/t92-011.

[40] Hyodo, M., Yasuhara, K., and Hirao, K. (1992). Prediction of clay behaviour in undrained and partially drained cyclic triaxial tests. Soils and Foundations, 32 (4), pp. 117-127.

[41] Lefebvre, G. and Pfendler, P. (1996). Strain rate and preshear effects in cyclic resistance of soft clay. Journal of Geotechnical Engineering, 122(1), pp. 21-26. doi: 10.1061/(ASCE)07339410(1996)122:1(21).

[42] Ansal, A.M., Iyisan, R., and Yildirim, H. (2001). The cyclic behaviour of soils and effects of geotechnical factors in microzonation. Soil Dynamics and Earthquake Engineering, 21(5), pp. 445-452. doi: 10.1016/S02677261(01)00026-4.

[43] Yasuhara, K., Murakami, S., Song, B.W., Yokokawa, S., and Hyde, A.F.L. (2003). Postcyclic degradation of strength and stiffness for low plasticity silt. Journal of Geotechnical and Geoenvironmental Engineering, 129(8), pp. 756-769. doi: 10.1061/(ASCE)10900241(2003)129:8(756).

[44] Yildirim, H. and Ersan, H. (2007). Settlements under consecutive series of cyclic loading. Soil Dynamics and Earthquake Engineering, 27(6), pp. 577-585. doi: 10.1016/j.soildyn.2006.10.007.

[45] Dahl, K. R., Dejong, J. T., Boulanger, R. W., Pyke, R., and Wahl, D. (2014). Characterization of an alluvial silt and clay deposit for monotonic, cyclic and postcyclic behavior. Canadian Geotechnical Journal, 51(4), pp. 432-440. doi: 10.1139/ cgj-2013-0057.

[46] Seed, H.B. and Chan, C.K. (1966). Clay strength under earthquake loading conditions. Soil Mechanics and Foundations Division, 92 (SM2), pp. 53-78.

[47] Yasuhara, K., Hirao, K., and Hyde, A.F.L. (1992). Effects of cyclic loading on undrained strength and compressibility 
of clay. Soils and Foundations, 32(1), pp. 100-116.

[48] Hyodo, M., Sugiyama, M., Yasufuku, N., Murata, H., and Kawata, Y. (1993). Cyclic shear behaviour of clay subjected to initial shear stress. Technical Report 2, Yamaguchi University.

[49] Hyodo, M., Yamamoto, Y., and Sugiyama, M. (1994). Undrained cyclic shear behaviour of normally consolidated clay subjected to initial static shear stress. Soils and Foundations, 34(4), pp. 1-11. doi: 10.3208/sandf1972.34.4_1.

[50] Yilmaz, M.T., Pekcan, O., and Turkey, B.S. (2004). Undrained cyclic shear and deformation behavior of silt clay mixtures of Adapazari, Turkey. Soil Dynamics and Earthquake Engineering, 24(7), pp. 497507. doi: 10.1016/j.soildyn.2004.04.002.

[51] Hyde, A.F.L., Higuchi, T., and Yasuhara, K. (2007). Post-cyclic recompression, stiffness, and consolidated cyclic strength of silt. Journal of Geotechnical and Environmental Engineering, 133(4), pp. 416-423. doi: 10.1061/(ASCE)10900241(2007)133:4(416).

[52] Okur, D. V. and Ansal, A. (2007). Stiffness degradation of natural fine grained soils during cyclic loading. Soil Dynamics and Earthquake Engineering, 27(9), pp. 843854. doi: 10.1016/j.soildyn.2007.01.005.

[53] Beroya, M.A.A., Aydin, A., and Katzenbach, R. (2009). Insight into the effects of clay mineralogy on the cyclic behavior of silt clay mixtures. Engineering Geology, 106(3-4), pp. 154-162. doi: 10.1016/j. enggeo.2009.03.006.
[54] Yasuhara, K. and Andersen, K.H. (1991). Recompression of normally consolidated clay after cyclic loading. Soils and Foundations, 31(1), pp. 83-94. doi: 10.3208/sandf1972.31.83.

[55] Vucetic, M. and Dobry, R. (1991). Effect of soil plasticity on cyclic response. Journal of Geotechnical Engineering, 117(1), pp. 89-107. doi: 10.1061/(ASCE)07339410(1991)117:1(89).

[56] Castro, G. and Christian, J.T. (1976). Shear strength of soils and cyclic loading. Journal of Geotechnical Engineering Division, 102 (GT9), pp. 887-894.

[57] Erken, A. and Ulker, B.M.C. (2007). Effect of cyclic loading on monotonic shear strength of fine-grained soils. Engineering Geology, 89(3-4), pp. 243-257. doi: 10.1016/j.enggeo.2006.10.008.

[58] Lee, K.L and Focht, J.A. (1976). Strength of clay subjected to cyclic loading. Marine Geotechnology, 3, pp. 165-185. doi: 10.1080/10641197609388162.

[59] Nieto-Leal, A. and Kaliakin, V. (2013). Behavior of cohesive soils subjected to cyclic loading "an extensive review of pertinent literature". Technical report, Department of Civil and Environmental Engineering, University of Delaware, Newark, DE. USA.

[60] Larew, H.G. and Leonards, G.G. (1962). A strength criterion for repeated loads. In Proceedings of the highway research board, 41, pp. 526-556.

[61] Wilson, N.E. and Elgohary, M.M. (1974). Consolidation of soils under cyclic loading. 
Canadian Geotechnical Journal, 11(3), pp. 420-423. doi: 10.1139/t74-042.

[62] Lefebvre, G., LeBoeuf, D., and Demers, B. (1989). Stability threshold for cyclic loading of saturated clay. Canadian Geotechnical Journal, 26(1), pp. 122-131. doi: 10.1139/t89-013.

[63] Vucetic, M. (1994). Cyclic threshold shear strains in soils. Journal of Geotechnical Engineering, 120(12), pp. 2208-2228. doi: 10.1061/(ASCE)07339410(1994)120:12(2208).

[64] Hsu, C.C. and Vucetic, M.V. (2006). Threshold shear strain for cyclic porewater pressure in cohesive soils. Journal of Geotechnical and Geoenvironmental Engineering, 132(10), pp. 13251335. doi: 10.1061/(ASCE)10900241(2006)132:10(1325).

[65] Díaz-Rodríguez, A. and Santamarina, J. C. (2001).MexicoCitysoilbehavioratdifferent strains: Observations and physical interpretation. Journal of Geotechnical and Geoenvironmental Engineering, 127(9), pp. 783-789. doi: 10.1061/(ASCE)10900241(2001)127:9(783).

[66] Santamarina, J. C. (2001). Soils and Waves. J. Wiley and Sons, Chichester, UK. in collaboration with Klein, K. and Fam, M.

[67] Díaz-Rodríguez, J.A. and López-Molina, J.A. (2008). Stress thresholds in soil dynamics. In The 14th World Conference on Earthquake Engineering, pp. 8.

[68] Zergoun, M. and Vaid, Y.P. (1994) Effective stress response of clay to undrained cyclic loading. Canadian
Geotechnical Journal, 31, pp. 714-727. doi: 10.1139/t94-083.

[69] Hyodo, M., Hyde, A., Yamamoto, Y., and Fujii, T. (1999). Cyclic shear strength of undisturbed and remolded marine clays. Soils and Foundations, 39(2), pp. 45-58.

[70] Saglam, S. and Sadik-Bakir, B. (2014). Cyclic response of saturated silts. Soil Dynamics and Earthquake Engineering, 61-62, pp. 164-175. doi: 10.1016/j. soildyn.2014.02.011.

[71] Lefebvre, G. and LeBoeuf, D. (1987). Rate effects and cyclic loading of sensitive clays. Journal of Geotechnical Engineering, 113(GT5), pp. 476-489. doi: 10.1061/ (ASCE)0733-9410(1987)113:5(476).

[72] Mesri, G. (2013). Discussion of "cyclic tests on high quality undisturbed block samples of soft marine Norwegian clay". Canadian Geotechnical Journal, 50(11), pp. 1188-1190. doi: 10.1139/cgj-20130331.

[73] Wichtmann, T., Andersen, K.H., Sjursen, M.A., and Berre, T. (2013). Cyclic tests on high-quality undisturbed block samples of soft marine Norwegian clay. Canadian Geotechnical Journal, 50(4), pp. 400-412. doi: 10.1139/cgj-2011-0390.

[74] Sangrey, D. A., Pollard, W. S., and Egan, J. A. (1978). Errors associated with rate of undrained cyclic testing of clay soils. Dynamic Geotechnical Testing, ASTM STP 654, pp. 280-294. doi: 10.1520/ STP35682S.

[75] Idriss, I.M., Moriwaki, Y., Wright, S.G., Doyle, E.H., and Ladd, R.S. (1980). 
Behavior of normally consolidated clay under simulated earthquake and ocean wave loading conditions. In International Symposium on Soils under Cyclic and Transient Loading, pp. 437-445.

[76] Lee, C.J. and Sheo, S.F. (2007). The stiffness degradation and damping ratio evolution of Taipei silty clay under cyclic straining. Soil Dynamics and Earthquake Engineering, 27, pp. 730-740.

[77] Zapata-Medina, D.G., Finno, R.J., and Vega-Posada, C.A. (2014). Stress history and sampling disturbance effects on monotonic and cyclic responses of overconsolidated Bootlegger Cove clays. Canadian Geotechnical Journal, 51, pp. 599-609.

[78] Gratchev, I.B. and Sassa, K. (2013). Cyclic shear strength of soil with different pore fluids. Journal of Geotechnical and Geoenvironmental Engineering, 139(10), pp. 1817-1821.

[79] Matsui, T., Bahr, M.A., and Abe, N. (1992). Estimation of shear characteristics degradation and stress-strain relationship of saturated clays after cyclic loading. Soils and Foundations, 32(1), pp. 161-172.

[80] Yasuhara,K.andHyde,A.F.L.(1997).Method for estimating postcyclic undrained secant modulus of clays. Journal of Geotechnical and Geoenvironmental Engineering, 123 (3), pp. 204-211. doi: 10.1061/(ASCE)10900241(1997)123:3(204).

[81] Wang, J., Guo, L., Cai, Y., Xu, C., and Gu, C. (2013). Strain and pore pressure development on soft marine clay in triaxial tests with a large number of cycles. Ocean Engineering, 74, pp. 125-132. doi: 10.1016/j.oceaneng.2013.10.005.

[82] Kvalstad, T.J. and Dahlberg, R. (1980). Cyclic behaviour of clay as measured in laboratory. In International Symposium on Soils under Cyclic and Transient Loading, pp. 157-167.

[83] Wang, S., Luna, R., and Yang, J. (2013). Postcyclic behavior of low plasticity silt with limited excess pore pressures. Soil Dynamics and Earthquake Engineering, 54, pp. 39-46. doi: 10.1016/j. soildyn.2013.07.016.

[84] Wang, S., Onyejekwe, S., and Yang, J. (2014). Threshold strain for postcyclic shear strength change of Mississippi river valley silt due to cyclic triaxial loading. Journal of Testing and Evaluation, ASTM, 42 (1), pp. 1-9. doi: 10.1520/JTE20120210. 